\title{
Gains in employment status following antidepressant medication or cognitive therapy for depression
}

\author{
Jay C. Fournier, Robert J. DeRubeis, Jay Amsterdam, Richard C. Shelton and Steven D. Hollon
}

\section{Background}

Depression can adversely affect employment status.

\section{Aims}

To examine whether there is a relative advantage of cognitive therapy or antidepressant medication in improving employment status following treatment, using data from a previously reported trial.

\section{Method}

Random assignment to cognitive therapy $(n=48)$ or the selective serotonin reuptake inhibitor paroxetine $(n=93)$ for 4 months; treatment responders were followed for up to 24 months. Differential effects of treatment on employment status were examined.

\section{Results}

At the end of 28 months, cognitive therapy led to higher rates of full-time employment (88.9\%) than did antidepressant medication among treatment responders $(70.8 \%), \chi^{2}{ }_{1}=5.78$, $P=0.02$, odds ratio $(\mathrm{OR})=5.66,95 \% \mathrm{Cl} 1.16-27.69$. In the shorter-term, the main effect of treatment on employment status was not significant following acute treatment $\left(\chi^{2}{ }_{1}=1.74, P=0.19, \mathrm{OR}=1.77,95 \% \mathrm{Cl} 0.75-4.17\right)$; however we observed a site $\times$ treatment interaction $\left(\chi^{2}{ }_{1}=6.87\right.$, $P=0.009$ ) whereby cognitive therapy led to a higher rate of full-time employment at one site but not at the other.

\section{Conclusions}

Cognitive therapy may produce greater improvements in employment $v$. medication, particularly over the longer term.

\section{Declaration of interest}

R.C.S. has served as a consultant for Bristol-Myers Squibb, Cerecor, Cyberonics, Eli Lilly, Forest Pharmaceuticals, Janssen Pharmaceutica, Medtronic, Naurex, Pamlab, Pfizer, Ridge Diagnostics, Shire and Takeda Pharmaceuticals. He has received research and/or grant support from Assurex, Cerecor, Elan Corp, Euthymics Bioscience, Forest Pharmaceuticals, Janssen Pharmaceutica, Jazz Pharmaceuticals, Naurex, Novartis Pharmaceuticals, Otsuka America, Pamlab, Pfizer, Repligen Corp, Ridge Diagnostics, St Jude Medical, and Takeda Pharmaceuticals.
Antidepressant medication and cognitive therapy are effective treatments for depression, ${ }^{1}$ with cognitive therapy showing an enduring effect beyond the end of treatment. ${ }^{2}$ There have been few studies of the comparative effect of these treatments on common and significant problems associated with depressive symptoms, such as deficits in occupational functioning. Rates of unemployment or underemployment are known to be high in samples of people with depression ${ }^{3}$ and depression can discourage the unemployed from seeking work. ${ }^{4}$ To date, there is a paucity of information on whether generic cognitive therapy for depression (i.e. cognitive therapy not specifically modified for job-finding elements) improves employment status compared with antidepressants. In this analysis, we examined whether antidepressants and cognitive therapy differed in their capacity to affect employment status among patients with moderate-to-severe major depressive disorder who were randomised to 4 months of treatment with antidepressants, cognitive therapy or a pill-placebo. Treatment responders were subsequently followed for up to 24 months. ${ }^{5}$

\section{Method}

\section{Participants}

A full description of the patient characteristics, treatment protocols and results of the primary analyses have been reported elsewhere. ${ }^{5,6}$ The study was conducted between 1996 and 2003 at the University of Pennsylvania and Vanderbilt University. The original sample consisted of 240 out-patients with major depressive disorder, ${ }^{7}$ ascertained with the Structured Clinical Interview for DSM-IV
Diagnosis. ${ }^{8}$ Inclusion in the study required a score of $\geqslant 20$ on the 17-item Hamilton Rating Scale for Depression (HRSD), ${ }^{9}$ modified to incorporate atypical symptoms. ${ }^{10}$ Exclusion criteria were: history of bipolar I disorder, active substance abuse or dependence, psychosis, previous failed response to study medications or the presence of another Axis I disorder that was judged to be primary. Also excluded were patients with antisocial, borderline or schizotypal personality disorders as assessed on the Structured Clinical Interview for DSM-III-R personality disorders. ${ }^{11}$ Patients were excluded at intake if they were judged to need immediate hospitalisation for suicide. Institutional review boards at each site approved the study protocol, and all patients provided written informed consent.

\section{Acute treatment}

Prior to entering the trial, patients were randomly assigned to receive cognitive therapy (cognitive therapy group, $n=60$ ), antidepressant medication (antidepressant group, $n=120$ ) or pill-placebo $(n=60)$. The pill-placebo was provided for 8 weeks; because of the short duration of this condition, it will not be considered further. Acute cognitive therapy and antidepressants were provided for 16 weeks.

For the first 8 weeks, antidepressant medication treatment was provided with paroxetine monotherapy. For the remaining 8 weeks, augmentation of paroxetine with desipramine or lithium was allowed, if clinically warranted. Administration of antidepressants and the pill-placebo was double blind for the first 8 weeks. Study pharmacotherapists conducted the medication 
management sessions in accordance with the clinical management manual $^{12}$ developed by J. Fawcett for use in the Treatment of Depression Collaborative Research Program. ${ }^{13}$ Training and consultation for the study pharmacotherapists was provided by J. Fawcett throughout the trial. A complete description of the adequacy of the dosing regimen can be found in the publication of the primary outcome findings. ${ }^{5}$

Six therapists provided cognitive therapy during the trial, three at each site. The qualifications of the therapists have been described elsewhere, ${ }^{5}$ and the degree to which therapists in this study adhered to the principles and techniques of cognitive therapy has been well characterised. ${ }^{14}$ Clinical evaluators, who were masked to treatment group (cognitive therapy, antidepressants or placebo) throughout the trial, conducted all assessments. As we reported previously, the two treatments produced comparable change in depressive symptom severity across the course of treatment and the response rates of each were superior to placebo. ${ }^{5}$ Thus, any observed differences in the effects of treatment on employment status could not simply be attributed to differential change in depressive symptoms.

\section{Follow-up}

Following acute treatment, treatment responders (see DeRubeis et $a l^{5}$ for a detailed description of treatment response) were followed for up to an additional 24 months. At the end of acute treatment, half of the antidepressant group responders were randomised to continuation medication (continuation antidepressant subgroup) and half to withdrawal onto a pill-placebo (placebo withdrawal subgroup). Cognitive therapy responders ceased regular contact with their therapists following acute treatment and were allowed up to three booster sessions. Patients were asked to refrain from receiving any other psychological or psychiatric treatments during the first 12-months of follow-up. As we reported previously, ${ }^{6}$ only two patients sought outside treatment, one in the cognitive therapy booster condition and one in the continuation antidepressant condition. These patients' data were censored at the time the new treatment was initiated for all subsequent analyses. After the first 12 months, all patients who remained relapse-free (and hence could be considered recovered) were withdrawn from all study treatments and followed naturalistically for an additional 12 months. ${ }^{6}$

\section{Outcome measures}

Depression symptom severity was ascertained with the HRSD and the Longitudinal Interval Follow-up Evaluation (LIFE) $)^{15}$ was used to track changes in employment status. Patients were assessed using the HRSD weekly for the first 4 weeks, every 2 weeks thereafter during acute treatment and at least monthly during follow-up. Assessments with the LIFE were conducted at intake, at the end of acute treatment and at least monthly during follow-up. In the event of attrition, data on the LIFE often continued to be collected. Because the LIFE is a retrospective tool, an individual's final work status prior to the point of attrition or loss to follow-up was used.

Vocational status was derived from the LIFE, which allows for 11 employment status codes. In this study, we examined data for individuals who obtained one of the following three work-related codes at baseline and at the end-point of interest: (a) full-time gainful employment; (b) part-time gainful employment (anything $30 \mathrm{~h}$ or less a week); or (c) unemployed but expected to work by self or others. These were treated as ordered categories in the analyses (see below). Patients were excluded from the analyses if they had no post-intake LIFE assessment, if they had missing data on the LIFE or if they were coded into one of the eight LIFE categories that were deemed unclassifiable: i.e. student, unemployed but not expected to work by self or others (e.g. physically disabled), retired, homemaker, leave of absence due to medical (non-psychiatric) reasons, part-time volunteer, full-time volunteer or other. Following Mintz and colleagues, ${ }^{16}$ we viewed such patients as outside of the active workforce and therefore excluded them from further consideration, as there was no systematic way to determine whether transitions into or out of these categories (if they occurred) were positive or negative. Figure 1 depicts the flow of participants through the study. The cognitive therapy and the antidepressant groups did not differ with respect to the percentages of participants whose data were excluded $\left(\chi^{2}{ }_{1}=0.15, P=0.70\right.$ during acute treatment; $\chi^{2}{ }_{1}=0.82, P=0.36$ during the continuation/follow-up phase).

\section{Data analysis}

When possible, differences between treatment conditions regarding work status were examined using ordinal logistic regression analyses. When this model was not appropriate, either because of the violation of the proportional odds assumption or low frequencies in one or more of the response categories, the outcome variable was dichotomised to represent those working full time $v$. those who were either unemployed or working part time. In either case, likelihood ratio chi-squared statistics and odds ratios (ORs) were estimated using PROC GENMOD in SAS 9.3 for Windows. Treatment effects were examined at the end of 4 months of acute treatment, and, for treatment responders, at the end of the 12-month continuation phase and at the end of the subsequent 12-month follow-up period, which represents the end of the 28-month assessment window from the point of intake. Unless otherwise stated, we examined the effects of treatment, site and the site $\times$ treatment interaction, controlling for intake depression severity and intake employment status. In the case of attrition, relapse or recurrence, the participant's last observation prior to termination was used for subsequent analyses.

\section{Results}

Figure 2 displays the rates of full-time employment and unemployment at intake $(n=141,48$ in the cognitive therapy group and 93 in the antidepressant group) and at the end of acute treatment for those initially randomised to the cognitive therapy or antidepressant groups, as well as the rates of full-time employment and unemployment for treatment responders ( $n=75,27$ in the cognitive therapy group and 48 in the antidepressant group) at the conclusion of the 12-month continuation and 24-month follow-up phases. At the end of the continuation and follow-up periods, very few individuals were unemployed; only $2(2.7 \%)$ at the end of continuation and 4 $(5.3 \%)$ at the end of follow-up, all of whom were in the group originally assigned to antidepressants. At these time points, we utilised logistic regression analyses to model full-time employment $v$. non-full-time employment (part-time employment or unemployment). Neither at the end of the 12 -month continuation phase nor at the subsequent 12-month follow-up phase was there a difference between the two antidepressant subgroups (i.e. the continuation antidepressant subgroup and the placebo withdrawal subgroup) on the rates of full-time employment $\left(\chi_{1}^{2}=0.02\right.$, $P=0.90$ for continuation phase; and $\chi^{2}{ }_{1}<0.00, P=0.98$ for follow-up phase), controlling for site, intake depression severity and intake employment status. Therefore, data from these two conditions $(n=48)$ were combined in subsequent analyses.

At the end of the 28-month assessment window, treatment responders in the cognitive therapy group were more likely to be full-time employed $\left(88.9 \%, \chi^{2}{ }_{1}=5.78, P=0.02, \mathrm{OR}=5.66,95 \%\right.$ 


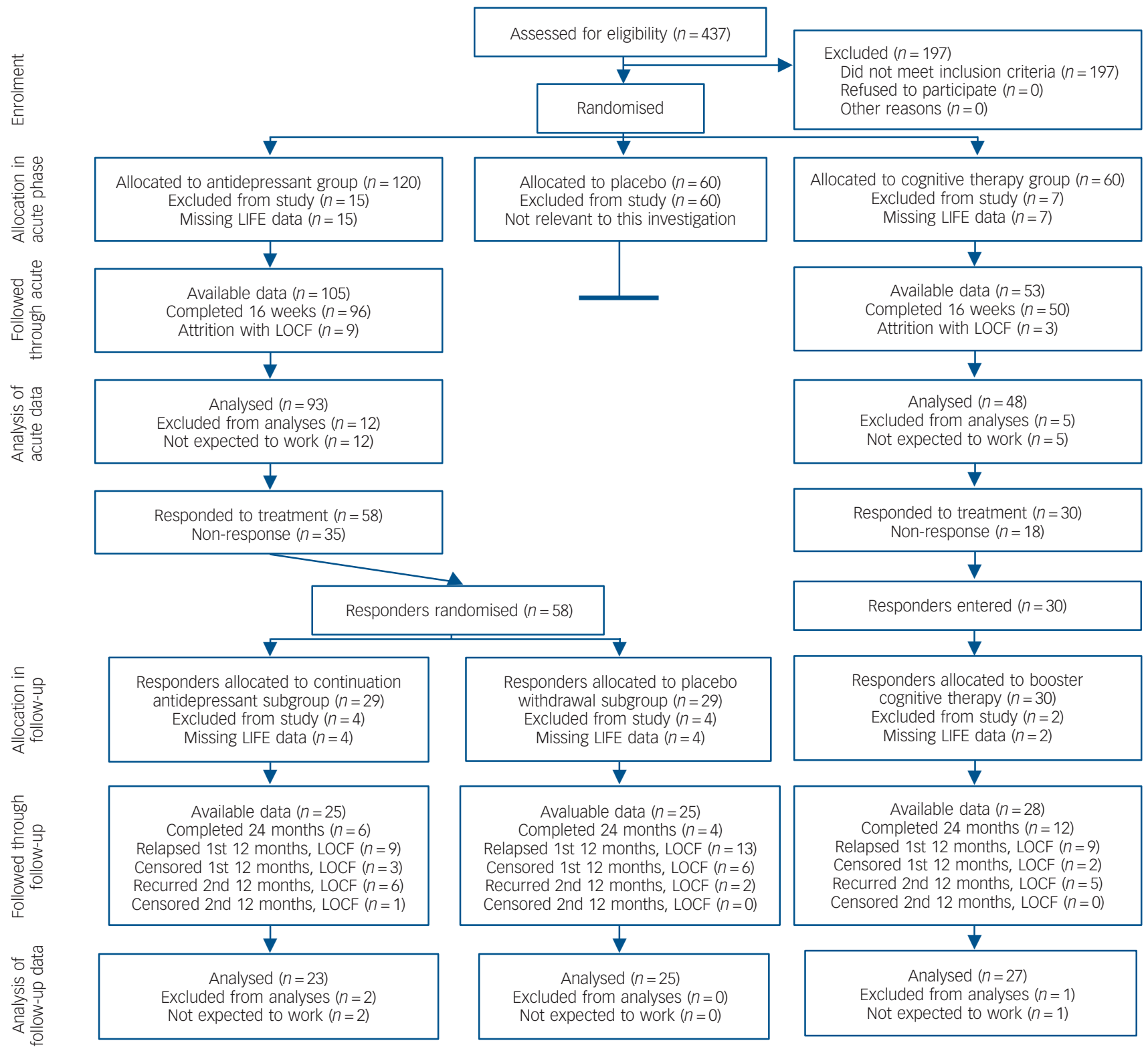

Fig. 1 Flow of participants through the trial.

LIFE, Longitudinal Interval Follow-up Evaluation; LOCF, last observation carried forward; Not expected to work, one of the eight LFE categories that were deemed unclassifiable.

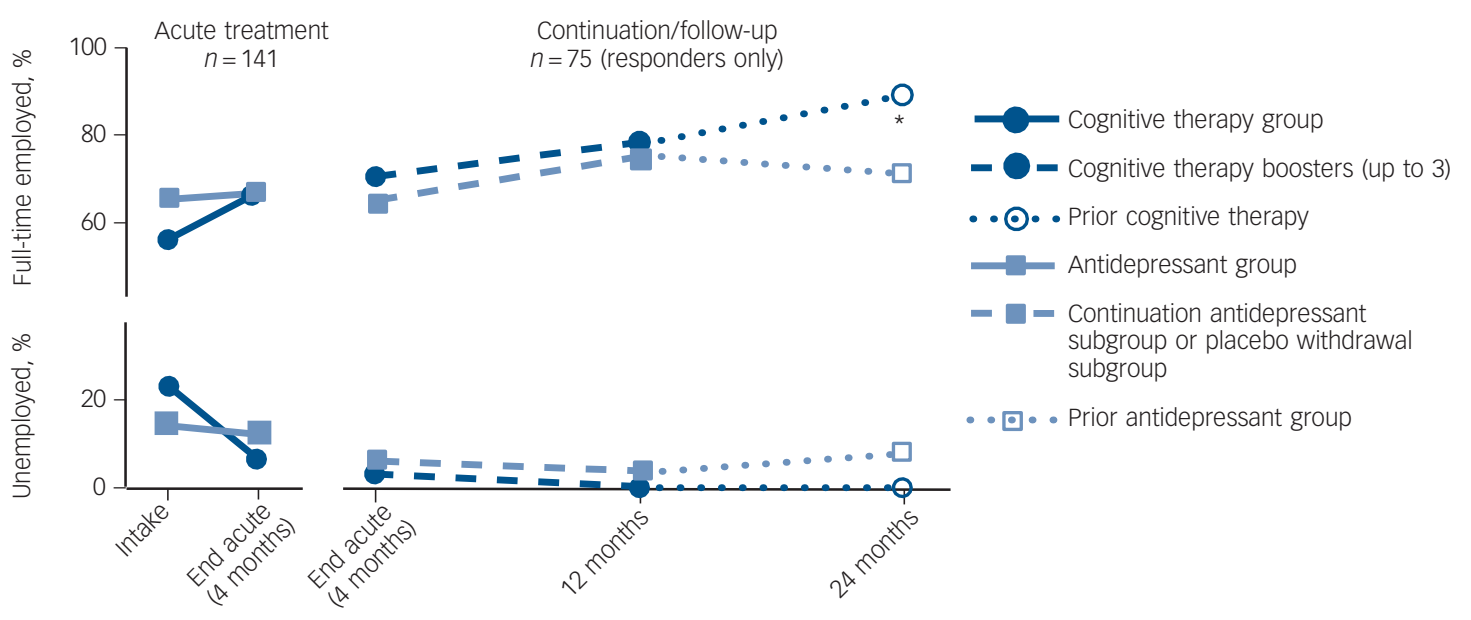

Fig. 2 Per cent employed full time and unemployed across the 28-month observation period.

The figure displays the percentages of individuals in each condition who were employed full time or who were unemployed; the percentage who were working part time can be calculated by subtracting the sum of the displayed categories from $100 \% .{ }^{*} P<0.05$. 
CI 1.16-27.69) relative to those in the antidepressant group (70.8\%). This effect did not differ as a function of site (site $\times$ treatment interaction $\left.\chi_{1}^{2}=0.08, P=0.78\right)$. There was no difference in the rate of full-time employment between the cognitive therapy $(77.8 \%)$ and the antidepressant $(75.0 \%)$ groups at the end of the first 12 -months of follow-up $\left(\chi_{1}^{2}=0.45, P=0.50, \mathrm{OR}=1.53\right.$, 95\% CI $0.43-5.46)$ nor was there a site $\times$ treatment interaction at the 12 -month assessment point $\left(\chi^{2}{ }_{1}=0.29, P=0.59\right)$, controlling for baseline depression severity and intake work status.

At the end of 16 weeks of acute treatment, the main effect of treatment on employment status was non-significant $\left(\chi_{1}^{2}=1.74\right.$, $P=0.19$, OR $=1.77,95 \%$ CI $0.75-4.17)$, but there was a significant site $\times$ treatment interaction $\left(\chi_{1}^{2}=6.87, P=0.009\right)$. At the University of Pennsylvania site, a significant treatment effect was observed $\left(\chi_{1}^{2}=10.85, P=0.001, \mathrm{OR}=9.36,95 \%\right.$ CI $\left.2.12-41.33\right)$ such that a larger percentage of individuals in the cognitive therapy group were full-time employed (59.1\%), relative to those assigned to the antidepressant group $(51.3 \%)$ and a smaller percentage were unemployed at the end of treatment $(4.6 \%$ for cognitive therapy v. $23.1 \%$ for antidepressant group). The treatment effect was not significant at the Vanderbilt site $\left(\chi_{1}^{2}=0.62, P=0.43\right.$, $\mathrm{OR}=0.62,95 \%$ CI $0.19-2.04)$, where the rates of full-time employment were $77.8 \%$ for the antidepressant group and $73.1 \%$ for the cognitive therapy group; the rates of unemployment were $3.7 \%$ and $7.7 \%$ respectively. The site $\times$ treatment interaction was observed in the context of large baseline differences in employment rates between sites $\left(\chi_{1}^{2}=5.45, P=0.02\right.$; Table 1$)$. That is, a higher percentage of individuals were employed fulltime at the Vanderbilt than at the University of Pennsylvania site $(71.3 \%$ v. $50.8 \%)$ and a lower percentage were unemployed at the Vanderbilt than at the University of Pennsylvania site $(13.8 \% v$. $21.3 \%)$. These site differences in intake work status did not differ as a function of treatment (site $\times$ treatment interaction: $\chi^{2}{ }_{1}=1.78$, $P=0.18$ ), nor did the two treatments differ with regard to intake employment status when data from the two sites were pooled $\left(\chi_{1}^{2}=1.57, P=0.21\right)$.

In secondary analyses, we observed no evidence of an effect of change in HRSD scores through acute treatment on employment status at the end of acute treatment $\left(\chi_{1}^{2}=0.56, P=0.45\right)$, controlling for intake employment status. Similarly, we observed no treatment $\times$ symptom-change interaction $\left(\chi^{2}{ }_{1}=0.07, P=0.79\right)$ or site $\times$ symptom-change interaction $\left(\chi_{1}^{2}=0.17, P=0.68\right)$ on employment status at the end of acute treatment. Indeed, the association between symptom change and work status was not significant in either treatment at either site (all $\chi_{1}^{2} \mathrm{~s} \leqslant 0.91$, Ps $>0.33$ ). Thus, we did not observe a significant relationship between change in symptoms and change in employment status during acute treatment.

\section{Discussion}

\section{Main findings}

Individuals who responded to a 4-month course of cognitive therapy were more likely to be employed full time 2 years later than were participants who responded to antidepressant medication. This pattern emerged despite the numerical advantage of antidepressant medication over cognitive therapy in the rates of full-time employment at the start of treatment. Across the 28-month assessment window, the rate of full-time employment improved by 33 percentage points in the cognitive therapy group, from $56 \%$ at intake to $89 \%$ at the end of follow-up, whereas the rate of full-time employment improved by only 5 percentage points, from $66 \%$ at intake to $71 \%$ at the end of follow-up, in the antidepressant group. For individuals who responded to cognitive therapy, the rates of full-time employment appeared to increase during the 24-month follow-up period, even after all therapeutic contact was terminated. By contrast, for those initially assigned to the antidepressant group, little change in employment status was observed. There was no indication that, among those who had responded to antidepressant medication, the rate of full-time employment was affected by medication continuation $v$. medication withdrawal during the follow-up period.

\section{Differences between treatment sites}

During acute treatment, cognitive therapy led to superior employment outcomes only at one of the two treatment sites. At the other site, the effect of treatment was not significant and the direction of the effect was reversed. It is not immediately clear why this pattern was observed. Fewer individuals were employed full time at the start of treatment at the University of Pennsylvania site, at which the significant treatment effect was observed, and there was numerically, although not significantly, less balance in the rates of full-time employment between treatments at that site. It is doubtful, however, that the site $\times$ treatment interaction can be explained either by ceiling effects at the Vanderbilt site or by an imbalance in baseline employment rates at the University of Pennsylvania site. That is, the findings from the 24-month follow-up period indicated that additional improvements in the rates of full-time employment were still possible, and all of our statistical models controlled for intake employment status. Two alternative hypotheses could explain the site differences in the effects of treatment on employment status: (a) there may have been local factors regarding the labour markets that differed between the two sites that may have made it more likely (at the University of Pennsylvania site) or less likely (at the Vanderbilt site) for individuals seeking employment to find it; or (b) there may have been subtle differences in the strategies and techniques used by cognitive therapists at each site. A careful examination of these competing hypotheses is beyond the scope of this paper, but future work should examine the roles of external, contextual factors as well as the specific elements of cognitive therapy that may be critical for improving employment outcomes.

\section{Findings from other studies}

To date, little prior work has examined differential effects of psychotherapy and medications on employment status, and even less is known about the mechanisms through which treatments for depression can affect employment outcomes. In 1992, Mintz

\begin{tabular}{|c|c|c|c|c|}
\hline & \multicolumn{2}{|c|}{ University of Pennsylvania, $n$ (\%) } & \multicolumn{2}{|c|}{ Vanderbilt University, $n$ (\%) } \\
\hline & $\begin{array}{l}\text { Antidepressant group } \\
\qquad(n=39)\end{array}$ & $\begin{array}{l}\text { Cognitive therapy group } \\
\qquad(n=22)\end{array}$ & $\begin{array}{l}\text { Antidepressant group } \\
\qquad(n=54)\end{array}$ & $\begin{array}{l}\text { Cognitive therapy group } \\
\qquad(n=26)\end{array}$ \\
\hline Full time & $23(59)$ & $8(36)$ & $38(70)$ & $19(73)$ \\
\hline Part time & $10(26)$ & $7(32)$ & $9(17)$ & $3(12)$ \\
\hline Unemployed & $6(15)$ & 7 (32) & $7(13)$ & $4(15)$ \\
\hline
\end{tabular}


and colleagues conducted what was at the time a comprehensive review of the association between treatments for depression and improvements in occupational functioning by acquiring and examining data from ten treatment studies. ${ }^{16}$ They observed that treatment with antidepressants was associated with improved work functioning compared with both placebo and psychotherapy. The comparison with psychotherapy, however, included just two studies, both of which examined cognitive therapy. One was a small study in which medication treatment was not placebo-controlled. ${ }^{17}$ In the other, cognitive therapy was not found to be superior to pill-placebo in reducing depressive symptoms, and it was less efficacious than antidepressants among patients with more severe depression. ${ }^{13}$ For this and other reasons, the quality with which cognitive therapy was administered in that latter trial has been questioned. ${ }^{18}$ Furthermore, Mintz and colleagues examined self-report ratings of job functioning - not changes in employment status per se.

A more recent meta-analysis ${ }^{19}$ examined the effects of depression treatments on more objective indicators of work outcomes, such as number of hours or days worked and employment status. These researchers identified only four studies; one was an efficacy trial of antidepressants $v$. placebo and three were effectiveness trials in primary care in which patients were encouraged but not required to participate in various treatments for depression, including pharmacotherapy and psychotherapy. Across the four studies, the estimated effect of treatment $v$. control on improving work-related functioning was small $(d=0.12)$. Similar findings have been reported in subsequent studies in primary care settings. ${ }^{20}$

An initial evaluation of the pilot programmes developed for the Improving Access to Psychological Therapies initiative in the UK revealed that cognitive-therapy-based interventions led to improved employment status for $5 \%$ of the patients treated. ${ }^{21}$ Additional research has found that group cognitive-behavioural training that incorporates specific employment-related components can facilitate job-finding in the long-term unemployed ${ }^{22}$ and in those receiving workers compensation. ${ }^{23}$ When prescribed appropriately, antidepressants have also been associated with increased employment among those receiving disability benefits. ${ }^{24,25}$ However, negative associations have been observed between receiving psychiatric treatments for depression (and other conditions) and labour-force participation and productivity. ${ }^{26}$

\section{Mechanisms underlying treatment effects}

Depression is a particularly debilitating disorder and problems in the vocational sphere are common. In an earlier article we reported that employment status moderated response to treatment such that patients who were unemployed responded better to cognitive therapy than to medication treatment. ${ }^{27}$ In this article we provide evidence that cognitive therapy had a direct effect on vocational status itself such that by the end of the follow-up period, a higher percentage of patients who had responded to cognitive therapy were employed full time, compared with patients who had responded to antidepressants.

The precise mechanisms through which cognitive therapy affected employment status in the current study are not yet clear. Similarly, it is not clear why the medication condition had relatively little effect on employment status. As we reported previously, the two active treatments were equally effective in improving depressive symptoms. ${ }^{5}$ As such, it is unlikely that the direct effects of cognitive therapy on depressive symptoms are responsible for the superior effects of cognitive therapy on employment status. Moreover, we did not observe any evidence in the current study to suggest a link between change in depressive symptoms and change in employment status during acute treatment, even at the site in which large treatment effects on employment status occurred. If confirmed in future studies, the lack of association between these two outcomes would suggest that change in depressive symptoms and change in employment status represent separate processes.

Cognitive change and cognitive skill acquisition have emerged as potential mediators of the therapeutic ${ }^{28,29}$ and relapse prevention ${ }^{30}$ effects of cognitive therapy for depression. It is not clear from the results of the current investigation whether these elements of cognitive therapy are responsible for the observed effects on employment status. In the course of cognitive therapy for depression as it is supposed to be practiced, patients are encouraged to use their own behaviours to test their negative beliefs and to increase their engagement in activities that foster the pursuit of goals they value. ${ }^{31}$ It is expected that therapists will help their patients plan a course of action that would lead to improvement in their vocational situation if those patients were unemployed or underemployed. As appropriate, behaviours are planned so as to facilitate the submission of job applications and role-plays are used to prepare individuals for any interviews that they might face. Cognitive restructuring can be used to help patients respond to any negative automatic thoughts that might interfere with the job search process, as well as core beliefs about the self that might undercut the motivation to act. All of these elements are available to therapists as a regular part of cognitive therapy, although it is not clear that they are always used. Future work is needed to test the hypothesis that behavioural and cognitive techniques that focus on employment-related topics can affect occupational status. Indeed, Lagerveld and colleagues observed that cognitive therapy that has been modified to incorporate a systematic focus on employment-related issues led to even greater improvements in occupational functioning than did standard cognitive therapy. ${ }^{32}$ A careful investigation of the mechanisms underlying these effects should be pursued.

\section{Limitations}

There are several limitations to the current study that should be noted. First, we opted to exclude those individuals from the analyses who were not expected to be pursuing involvement in the workforce. It is possible that the exclusion of these individuals, as well as those with missing data, could have had an impact on the findings. However, we note that the two treatment conditions did not differ with regard to the percentage of patients whose data were excluded. Nevertheless, our results are most applicable to those who were expected to be employed or actively seeking gainful employment. Future studies should examine change in employment status as a primary outcome using carefully designed instruments that track changes in employment status as well as the patient's subjective experience of those changes.

Second, we used the last observation prior to attrition or loss to follow-up for those patients who dropped out of treatment or follow-up. It is difficult to know whether the work statuses of these individuals would have changed had they remained in treatment or in the study. We opted for the relatively conservative approach of continuing to include these individuals whenever possible, and we assumed in our models that their work statuses would not have changed further.

Third, the analyses we described were not pre-planned during the design of the parent trial. As such, independent confirmation from a trial designed specifically to examine differential change in employment status will be needed before definitive conclusions can be made about the relative efficacy of cognitive therapy and antidepressants regarding employment outcomes. Related to this, because the study from which these data originated was not designed with these questions in mind, the timing of the work status assessments did not allow for more fine-grained analyses of the time course of work status change or for an examination 
of the causal links between work-status change, symptom change and changes in other clinical and functioning measures. Future work should include the collection of such data at multiple time points throughout treatment and follow-up so that questions about the mechanisms underlying treatment differences can be examined.

Fourth, the study from which these data originated examined only one antidepressant medication, the selective serotonin reuptake inhibitor (SSRI) paroxetine, allowing for augmentation after 8 weeks. There is some evidence that medications from different classes have different effects of social and occupational functioning. ${ }^{33}$ Additional research is needed to compare cognitive therapy with other medications that may affect different neurotransmitter systems.

Fifth, the findings from this study are quite likely to be affected by external economic forces. The data from this study were collected at a particular time (the late 1990s and early 2000s) and in a particular economic context. It is possible that similar findings would not obtain in other contexts or during other time periods, and efforts should be made to replicate the current findings across different settings. Nevertheless, the current findings suggest that cognitive therapy can lead to better work status outcomes than an SSRI in conditions in which improvement in one's work status is possible.

Finally, the sample sizes in this study, particularly for comparisons in the continuation phase, were small. Independent replication of the findings using larger samples should be pursued. Despite this, we observed a clear pattern whereby cognitive therapy led to better employment outcomes than did antidepressants at the University of Pennsylvania site during acute treatment and across the two sites by the end of the 2-year follow-up for treatment responders.

\section{Implications}

Psychotherapy has lost market share to treatment with medication over the past two decades in the USA. ${ }^{34,35}$ The newer antidepressants are safe enough that general practitioners are comfortable prescribing them, and it only costs about half as much to treat a patient to remission with medications as it does with cognitive therapy. ${ }^{6,36}$ However, there are indications that cognitive therapy has an enduring effect (evidence coming from the reduced risk for relapse and recurrence following successful treatment) that is not found for medication. Thus, cognitive therapy may be more cost-effective in the long run., ${ }^{6,36}$ Insofar as it increases the likelihood that patients who are unemployed will not only respond to treatment ${ }^{27}$ but also achieve a higher vocational status, given the right context, cognitive therapy would appear to be the treatment of choice for patients who are unemployed, all else equal. These considerations played a role in the decision by the UK government to invest more that $\mathfrak{E 7 0 0}$ million in the UK National Health Service, specifically to train therapists in the empirically supported psychotherapies, including cognitive therapy for depression. ${ }^{37}$

\footnotetext{
Jay C. Fournier, PhD, Department of Psychiatry, University of Pittsburgh School of Medicine, Pittsburgh, Pennsylvania; Robert J. DeRubeis, PhD, Department of Psychology, University of Pennsylvania, Philadelphia, Pennsylvania; Jay Amsterdam MD, Department of Psychiatry, Perelman School of Medicine, University of Pennsylvania, Philadelphia, Pennsylvania; Richard C. Shelton, MD, Department of Pennsylvania, Philadelphia, Pennsylvania; Richard C. Shelton, MD, Department of
Psychiatry and Behavioral Neurobiology, The University of Alabama at Birmingham, Birmingham, Alabama; Steven D. Hollon, PhD, Department of Psychology, Vanderbilt University, Nashville, Tennessee, USA

Correspondence: Jay C. Fournier, PhD, Department of Psychiatry, University of Pittsburgh School of Medicine, Western Psychiatric Institute and Clinic, 3811 O'Hara Street, Pittsburgh, PA 15213, USA. Email: fournierjc@upmc.edu

First received 12 Jun 2013, final revision 3 Mar 2014, accepted 14 Mar 2014
}

\section{Funding}

This research was supported by grants MH55877 (R10 PI to R.J.D.) and MH55875 (R10 PI to S.D.H.) from the National Institute of Mental Health, Bethesda, MD. J.A. receives grant support from NIMH grants MH06099, MH060353, MH080097, MH077580, and NIH/NCCAM grant AT005074. J.C.F. receives grant support from NIMH grant MH097889. GlaxoSmithKline provided medications and pill-placebos for the trial.

\section{References}

1 American Psychiatric Association. Treatment of Patients with Major Depressive Disorder (3rd edn). APA, 2010.

2 Cuijpers $\mathrm{P}$, Hollon SD, van Straten A, Bockting C, Berking M, Andersson G. Does cognitive behaviour therapy have an enduring effect that is superior to keeping patients on continuation pharmacotherapy? A meta-analysis. BMJ Open 2013; 3: e002542.

3 Warr $\mathrm{P}$, Jackson $\mathrm{P}$, Banks $\mathrm{M}$. Unemployment and mental health: some British studies. J Soc Issues 1988; 44: 47-68.

4 Feather N. The Psychological Impact of Unemployment. Springer-Verlag, 1990.

5 DeRubeis RJ, Hollon SD, Amsterdam JD, Shelton RC, Young PR, Salomon RM, et al. Cognitive therapy vs medications in the treatment of moderate to severe depression. Arch Gen Psychiatry 2005; 62: 409-16.

6 Hollon SD, DeRubeis RJ, Shelton RC, Amsterdam JD, Salomon RM, O'Reardon JP, et al. Prevention of relapse following cognitive therapy vs medications in moderate to severe depression. Arch Gen Psychiatry 2005; 62: 417-22.

7 American Psychiatric Association. Diagnostic and Statistical Manual of Mental Disorders (4th edn, text revised) (DSM-IV-TR). APA, 2000.

8 First M, Spitzer R, Gibbon M, Williams J. Structured Clinical Interview for DSM-IV-TR- Axis I Disorders, Research Version, Patient Edition With Psychotic Screen (SCID-I/P W/ PSY SCREEN). Biometrics Research, New York State Psychiatric Institute, 2001

9 Hamilton MA. A rating scale for depression. J Neurol Neurosurg Psychiatry 1960; 23: 56-62.

10 Reimherr FW, Amsterdam JD, Quitkin FM, Rosenbaum JF, Fava M, Zajecka J, et al. Optimal length of continuation therapy in depression: a prospective assessment during long-term fluoxetine treatment. Am J Psychiatry 1998; 155: $1247-53$

11 Spitzer R, Williams J, Gibbon M, First M. Structured Clinical Interview for DSM-IIR Personality Disorders (SCID-II, Version 1.0). American Psychiatric Press, 1990.

12 Fawcett J, Epstein $\mathrm{P}$, Fiester SJ, Elkin I, Autry JH. Clinical managementimipramine/placebo administration manual: NIMH treatment of depression collaborative research program. Psychopharmacol Bull 1987; 23: 309-24.

13 Elkin I, Shea MT, Watkins JT, Imber SD, Sotsky SM, Collins JF, et al. National Institute of Mental Health Treatment of Depression Collaborative Research Program: general effectiveness of treatments. Arch Gen Psychiatry 1989; 46: 971-82.

14 Strunk DR, Brotman MA, DeRubeis RJ, Hollon SD. Therapist competence in cognitive therapy for depression: predicting subsequent symptom change. J Consult Clin Psychol 2010; 78: 429-37.

15 Keller MB, Lavori P, Friedman B, Nielsen E, Endicott J, McDonald-Scott P, et al. The Longitudinal Interval Follow-up Evaluation. Arch Gen Psychiatry 1987; 44: 540-8.

16 Mintz J, Mintz LI, Arruda MJ, Hwang SS. Treatments of depression and the functional capacity to work. Arch Gen Psychiatry 1992; 49: 761-8.

17 Murphy GE, Simons AD, Wetzel RD, Lustman PJ. Cognitive therapy and pharmacotherapy: singly and together in the treatment of depression. Arch Gen Psychiatry 1984; 41: 33.

18 Jacobson NS, Hollon SD. Cognitive-behavior therapy versus pharmacotherapy: now that the jury's returned its verdict, it's time to present the rest of the evidence. J Consult Clin Psychol 1996; 64: $74-80$.

19 Timbie JW, Horvitz-Lennon M, Frank RG, Normand SLT. A meta-analysis of labor supply effects of interventions for major depressive disorder. Psychiatr Serv 2006; 57: 212-8.

20 Wang PS, Simon GE, Avorn J, Azocar F, Ludman EJ, McCulloch J, et al. Telephone screening, outreach, and care management for depressed workers and impact on clinical and work productivity outcomes. JAMA 2007; 298: 1401-11.

21 Clark DM, Layard R, Smithies R, Richards DA, Suckling R, Wright B. Improving access to psychological therapy: initial evaluation of two UK demonstration sites. Behav Res Ther 2009; 47: 910-20. 
22 Proudfoot J, Guest D, Carson G, Gray J. Effect of cognitive-behavioural training on job-finding among long-term unemployed people. Lancet 1997; 350: 96-100.

23 Della-Posta C, Drummond PD. Cognitive behavioural therapy increases re-employment of job seeking worker's compensation clients. J Occup Rehabil 2006; 16: 217-24.

24 Smith EG, Henry AD, Zhang J, Hooven F, Banks SM. Antidepressant adequacy and work status among medicaid enrollees with disabilities: a restrictionbased, propensity score-adjusted analysis. Community Ment Health J 2009; 45: 333-40.

25 Dewa CS, Hoch JS, Lin E, Paterson M, Goering P. Pattern of antidepressant use and duration of depression-related absence from work. Br J Psychiatry 2003; 183: 507-13.

26 Waghorn G, Chant D. Receiving treatment, labor force activity, and work performance among people with psychiatric disorders: results from a population survey. J Occup Rehabil 2011; 21: 547-58.

27 Fournier JC, DeRubeis RJ, Shelton RC, Hollon SD, Amsterdam JD, Gallop R. Prediction of response to medication and cognitive therapy in the treatment of moderate to severe depression. J Consult Clin Psychol 2009; 77: 775-87.

28 Quilty LC, MCBride C, Bagby RM. Evidence for the cognitive mediational model of cognitive behavioural therapy for depression. Psychol Med 2008; 38: 1531-41.

29 DeRubeis RJ, Evans MD, Hollon SD, Garvey MJ, Grove WM, Tuason VB. How does cognitive therapy work? Cognitive change and symptom change in cognitive therapy and pharmacotherapy for depression. J Consult Clin Psychol 1990; 58: 862-9.
30 Strunk DR, DeRubeis RJ, Chiu AW, Alvarez J. Patients' competence in and performance of cognitive therapy skills: Relation to the reduction of relapse risk following treatment for depression. J Consult Clin Psychol 2007; 75: 523-30.

31 Beck AT, Rush AJ, Shaw BF, Emery G. Cognitive Therapy of Depression. The Guilford Press, 1979.

32 Lagerveld SE, Blonk RW, Brenninkmeijer V, Wijngaards-de Meij L, Schaufeli WB. Work-focused treatment of common mental disorders and return to work: a comparative outcome study. J Occup Health Psychol 2012; 17: 220-34.

33 Venditti $\mathrm{LN}$, Arcelus $\mathrm{A}$, Birnbaum $\mathrm{H}$, Greenberg $\mathrm{P}$, Barr $\mathrm{CE}$, Rowland $\mathrm{C}$ et al. The impact of antidepressant use on social functioning: reboxetine versus fluoxetine. Int Clin Psychopharmacol 2000; 15: 279-89.

34 Olfson M, Marcus SC, Druss B, Elinson L, Tanielian T, Pincus HA. National trends in the outpatient treatment of depression. JAMA 2002; 287: 203-9.

35 Marcus SC, Olfson M. National trends in the treatment of depression from 1998 to 2007. Arch Gen Psychiatry 2010; 67: 1265-73.

36 Dobson KS, Hollon SD, Dimidjian S, Schmaling KB, Kohlenberg RJ, Gallop RJ, et al. Randomized trial of behavioral activation, cognitive therapy, and antidepressant medication in the prevention of relapse and recurrence in major depression. J Consult Clin Psychol 2008; 76: 468-77.

37 Clark DM. Implementing NICE guidelines for the psychological treatment of depression and anxiety disorders: the IAPT experience. Int Rev Psychiatry 2011; 23: 375-84 